\title{
Lexicografia Pedagógica: uma proposição prática exemplificada
}

Pedagogical Lexicography: an exemplified practical proposition

\author{
Maria da Graça Krieger* \\ Alexandra Feldekircher Müller **
}

\begin{tabular}{|c|c|}
\hline $\begin{array}{l}\text { RESUMO: A Lexicografia Pedagógica } \\
\text { (LP) é motivada pela compreensão do } \\
\text { importante papel didático que os } \\
\text { dicionários podem desempenhar no } \\
\text { ensino/aprendizagem das línguas. Um } \\
\text { dos objetivos da Lexicografia Pedagógica } \\
\text { consiste, portanto, em evidenciar a } \\
\text { produtividade do dicionário em } \\
\text { diferentes situações de aprendizado não } \\
\text { só de língua estrangeira, mas também da } \\
\text { língua materna. Neste artigo, salienta-se a } \\
\text { importância das relações entre níveis e/ou } \\
\text { projetos de ensino e a proposta } \\
\text { lexicográfica que rege a organização } \\
\text { estrutural de dicionários escolares de } \\
\text { língua materna. Estudos de LP constatam } \\
\text { a carência de formação em lexicografia } \\
\text { dos professores no Brasil. Isso explica o } \\
\text { desconhecimento da estrutura e do } \\
\text { potencial de lições sobre a língua e a } \\
\text { linguagem que os dicionários oferecem. } \\
\text { Consequentemente, evidencia-se o pouco } \\
\text { aproveitamento dos dicionários nas } \\
\text { práticas pedagógicas de língua materna. } \\
\text { No entanto, percebe-se que os princípios } \\
\text { da LP vêm produzindo impactos } \\
\text { positivos sobre a produção editorial da }\end{array}$ & $\begin{array}{l}\text { ABSTRACT: Pedagogical Lexicography } \\
\text { (LP) is motivated by the understanding of } \\
\text { the important didactic role that } \\
\text { dictionaries can play in teaching } \\
\text { learning languages. One of the objectives } \\
\text { of Pedagogic Lexicography consists in } \\
\text { evidencing the productivity of the } \\
\text { dictionary in different situations of } \\
\text { learning not only of foreign language, but } \\
\text { also of the mother tongue. In this article, } \\
\text { we highlight the importance of the } \\
\text { relation between levels and / or teaching } \\
\text { projects and the lexicographic proposal } \\
\text { that rules the structural organization of } \\
\text { mother tongue language dictionaries. LP } \\
\text { studies confirm the deficiency of teacher } \\
\text { lexicography training in Brazil. This } \\
\text { explains the lack of knowledge of the } \\
\text { structure and potential of lessons about } \\
\text { language and language that dictionaries } \\
\text { offer. Consequently, the little use of } \\
\text { dictionaries in mother-tongue } \\
\text { pedagogical practices is evident. } \\
\text { However, it is perceived that the } \\
\text { principles of LP have produced positive } \\
\text { impacts on the editorial production of } \\
\text { Brazilian school lexicography. In this }\end{array}$ \\
\hline
\end{tabular}

\footnotetext{
* Doutora em Linguística e Semiótica - USP. Universidade do Vale do Rio dos Sinos - UNISINOS. kriegermg@gmail.com.

** Doutora em Linguística Aplicada - UNISINOS. Universidade do Vale do Rio dos Sinos - UNISINOS. alexandra.f.m@gmail.com; alexandrafm@unisinos.br.
} 
lexicografia escolar brasileira. Nesse contexto, este texto tem por objetivo apresentar resultados de um trabalho prático, publicado sob a forma de Caderno de Exercícios (KRIEGER; MÜLLER, 2017). Dois eixos pautam a organização dos Cadernos: 1) Para conhecer e consultar o dicionário e 2) Para aproveitar o dicionário. Todo o material compreende um conjunto de 90 exercícios que podem auxiliar os professores em diversas atividades didáticas com o uso de dicionários.

PALAVRAS-CHAVE: Dicionário escolar. Lexicografia Pedagógica. Exercícios. Atividades didáticas. context, this text aims to present the results of a practical work, published in the form of Caderno de Exercícios (KRIEGER; MÜLLER, 2017). Two axes guide the organization of the Notebooks: 1) To know and consult the dictionary and 2) To take advantage of the dictionary. All the material includes a set of 90 exercises that can help teachers in various didactic activities with the use of dictionaries.

\section{Introdução}

Falar em Lexicografia Pedagógica (LP) pressupõe a definição de princípios teóricos e metodológicos que cobrem as principais relações entre dicionários e ensino. O desenvolvimento dessas relações fundamenta-se na motivação primeira da Lexicografia Pedagógica: tornar o uso do dicionário produtivo e orientado para o ensino das línguas. Em decorrência, além da qualidade, a adequação da obra a ser trabalhada com os alunos e o projeto didático do professor precisam estar em harmonia. A compatibilidade desses dois fatores consiste numa condição qualitativa para que o dicionário, um tipo de obra ainda pouco explorada, efetivamente, torne-se um recurso didático produtivo no ensino/aprendizagem da língua materna, contexto aqui privilegiado.

O alinhamento desses fatores torna-se relevante nas proposições básicas da Lexicografia Pedagógica, domínio de conhecimento ainda novo não só no Brasil, mas também no panorama internacional, e que integra o campo de estudos da Lexicografia. Observa-se, no entanto, que, mesmo antes do desenvolvimento de estudos lexicográficos sistemáticos, vale dizer, antes que a Lexicografia tenha sido reconhecida 
como um ramo da Linguística Aplicada, já era disseminada a concepção de que o dicionário cumpre funções didáticas não só no ensino de línguas estrangeiras, mas também no da língua materna. Tanto assim é que as obras lexicográficas sempre estiveram incluídas nas relações de material didático, junto à indicação dos livros necessários a cada série escolar. Essa inclusão "natural" é, de algum modo, responsável pela ideia de que o professor sabe e sempre soube aproveitar bem o dicionário em seus ensinamentos.

Entretanto, a realidade não é essa e não apenas no nosso país. Verifica-se o mesmo tipo de problema até em países de larga tradição lexicográfica como a Espanha, onde foi desenvolvida uma pesquisa com o objetivo de medir os graus de interação que o dicionário tem no âmbito do ensino do espanhol como língua materna. A responsável pela investigação diz:

Nuestra hipótesis de partida se halla en el supuesto de que, aunque la llamada "lexicografía didáctica" ha experimentado un espectacular desarrollo en los últimos tiempos, el lugar que ocupa el diccionario en la enseñanza del español está lejos de alcanzar el que le corresponde, teniendo en cuenta su reconocida utilidad como instrumento de aprendizaje. (AZORIN FERNANDES, 2007, p. 169) ${ }^{1}$.

O Brasil também sofre esse distanciamento, conforme vários estudos acadêmicos têm mostrado. Tal distanciamento é também uma das importantes motivações para o impulso da Lexicografia Pedagógica direcionada à língua materna. Entre outros aspectos, essa linha de investigação tenta romper, com o "desconhecimento" dos dicionários, em especial, daquelas obras cujas propostas lexicográficas são voltadas ao ensino em vários níveis. Contribuir para minimizar esse

\footnotetext{
${ }^{1}$ Nossa hipótese de partida baseia-se no pressuposto de que, ainda que a chamada "lexicografia didática" tenha experimentado um espetacular desenvolvimento nos últimos tempos, o lugar que o dicionário ocupa no ensino do espanhol está longe de alcançar aquilo que ele de fato representa, levando em conta a sua reconhecida utilidade como instrumento de aprendizagem. (Tradução nossa).
} 
desconhecimento motiva o desenvolvimento deste artigo que apresenta alguns resultados de uma proposta de produção de material didático, cujo fim último é colaborar para diminuir a carência de materiais que auxiliem o professor a aproveitar o potencial didático do dicionário em seu projeto pedagógico de ensino/aprendizagem da língua portuguesa quer nas séries iniciais ou finais do Ensino Fundamental ou mesmo nas do Ensino Médio.

Trata-se de uma publicação ${ }^{2}$ que propõe exercícios, relacionando-os a habilidades e competências que, em geral, são exigidas no ensino da língua portuguesa como leitura, produção textual descrição da língua entre outros temas. Não se trata de um trabalho que pretende ser um modelo acabado. Diferentemente, a proposição de exercícios, adiante exemplificados, limita-se a sugestões de uso do dicionário a uma aplicação prática resultante de reflexões e estudos sobre o potencial do dicionário de língua no processo de aprendizado.

\section{Avanços em Lexicografia Pedagógica}

É importante lembrar que a Lexicografia Pedagógica no Brasil tem avançado, destacando-se tanto o plano da reflexão acadêmica, como o plano da produção lexicográfica editorial, destinada à escola. No campo editorial, é preciso reconhecer que a adoção de políticas públicas que valorizaram os dicionários como importantes instrumentos didáticos respondem largamente pelos impactos positivos nos modelos lexicográficos.

Por sua vez, a produção científica acadêmica, aqui referida, situa-se no âmbito dos pesquisadores de Ciências do Léxico, marcadamente no domínio da Lexicografia. Isso ocorre a partir do final do século $X X$, ampliando-se as proposições e análises críticas sobre dicionários escolares utilizados no Brasil. $\mathrm{Na}$ realidade, a pesquisa

\footnotetext{
${ }^{2}$ Caderno Interativo: atividades com o dicionário, publicado pela Editora Lexikon no ano de 2017, de autoria de Maria da Graça Krieger e Alexandra Feldekircher Müller.
} 
brasileira vem acompanhando o desenvolvimento internacional da Lexicografia Pedagógica, cujo pioneirismo concerne às línguas estrangeiras. Posteriormente, ganha também impulso o foco da produtiva utilização dos dicionários em relação aos ensinamentos de língua materna. Com desenvolvimento semelhante, constrói-se, em nosso meio, um panorama que se expande e cobre a problemática da qualidade e das funções dos dicionários de uso escolar para o ensino/aprendizado seja de língua estrangeira, seja de língua materna. O detalhamento desse panorama foge ao escopo deste artigo. Não obstante, é importante registrar que vários pesquisadores do grupo das Ciências do Léxico ${ }^{3}$ têm contribuído para a consistência das reflexões e análises críticas relacionadas à Lexicografia e ao aprendizado de línguas.

Sem dúvida, os estudos de Lexicografia Pedagógica revestem-se de importância já que podem orientar escolhas e práticas didáticas que envolvem o uso de dicionários. Abrir caminhos a um uso produtivo e orientado dos dicionários, nesse cenário, é missão da LP. Logo, o dicionário, identificado como escolar ou assim chamado, é o objeto primeiro de estudo da Lexicografia Pedagógica. Isso não significa fechar o pensamento numa concepção única, num modelo exclusivo e excludente, mas avaliar a adequação da obra lexicográfica escolhida, considerando o projeto de ensino do professor. Logicamente, a qualidade é condição implícita de todo e qualquer dicionário considerado adequado ao nível de escolaridade e ao projeto didático dos professores.

Nessa ótica, inscreve-se a atual produção lexicográfica brasileira dirigida à escola. Esse segmento, a partir de 2006, cresceu quantitativa e qualitativamente na relação direta das proposições do Programa Nacional do Livro Didático (PNLD). Trata-se de antiga política do Ministério de Educação, fundada em rigoroso processo

\footnotetext{
${ }^{3}$ http://anpoll.org.br/gt/lexicologia-lexicografia-e-terminologia/. Esse grupo publica seus trabalhos sob a forma de uma coleção intitulada Ciências do Léxico: Lexicologia, Lexicografia, Terminologia.
} 
seletivo para a aquisição de livros didáticos para o ensino público no nível Fundamental.

Desde 2001, o PNLD ressaltou a função didática que os dicionários podem exercer no ensino da língua materna, incluindo esse tipo de obra em seu processo seletivo de obras para as escolas públicas. Inicialmente, os editais referiam a seleção de dicionário escolar sob o formato único de minidicionário, seguindo uma larga tradição conceitual que veio a ser rompida pelo PNLD de 2006. Nesse Programa, foi realizada uma profunda inovação, ao serem abertas inscrições para seleção de três categorias de dicionários, consideradas necessárias à aprendizagem de diferentes fases do Ensino Fundamental. Em grandes linhas, as três categorias com os critérios definidores dos tipos de dicionários selecionados para a escola pública do país foram identificadas numericamente, junto à exigência de uma organização estrutural compatível com os níveis de aprendizagem, conforme explicitado nos editais da época: - Dicionários de tipo 1 - Número de entradas: mínimo de 1000 e máximo de 3000. Proposta lexicográfica adequada à introdução do alfabetizando ao gênero dicionário.

- Dicionários de tipo 2 - Número de entradas: mínimo de 3.500, máximo de 10.000. Proposta lexicográfica adequada a alunos em fase de consolidação do domínio da escrita.

- Dicionários de tipo 3 - Número de verbetes: mínimo de 19.000 e máximo de 35.000. Proposta lexicográfica orientada pelas características de um dicionário padrão, porém adequada a alunos das últimas séries do primeiro segmento do Ensino Fundamental.

A categorização apresentada é bastante genérica, mas salienta um aspecto fundamental: a relação entre proposta lexicográfica e nível de ensino. O PNLD passa então a exigir que toda obra seja estruturada em moldes que atendam a necessidades dos usuários previstos, oferecendo informações compatíveis com suas capacidades cognitivas e considerando as etapas de aprendizado do Ensino Fundamental. É interessante observar ainda que a referência a tipos 1, 2 e 3 foi propositadamente estabelecida como forma de fugir de títulos comuns e, em geral, aleatórios que recebem 
obras que circulam no mercado editorial a exemplo de dicionário infantil, infantojuvenil, escolar. Entre outras, essas citadas são denominações livremente escolhidas e nem sempre pertinentes.

O PNLD continuou avançando e aprimorando seu alcance, ao incluir novas categorias em anos subsequentes, como a criação da categoria do Ensino Médio. Importa destacar que todas essas ações de uma política pública educacional provocaram um impacto positivo fundamental na produção lexicográfica brasileira direcionada à escola. Nesse quadro positivo, dois aspectos essenciais merecem destaque: a alteração do tradicional conceito de dicionário escolar e a exigência de adequação da proposta lexicográfica de cada tipo de obra. De modo particular, abalouse a arraigada ideia de que minidicionário e dicionário escolar são sinônimos praticamente perfeitos. Tal compreensão justificava-se em razão do minidicionário ser uma obra bem mais concisa do que um dicionário geral de língua; consequentemente, um livro menos pesado para o aluno carregar em sua mochila. Bem entendido, eram outros tempos, caracterizados pela existência única do livro em papel. Entretanto, a definição dos critérios de concisão para compor a nomenclatura de um minidicionário, bem como de outros aspectos estruturais, nunca foram claramente explicitados, pelo menos, na Lexicografia brasileira mais difundida.

O redimensionamento da concepção de dicionário escolar, determinado pelo PNLD, evidencia a inclusão do Programa no âmbito da Lexicografia Pedagógica tanto no plano conceitual, quanto aplicado, já que o mercado editorial do Brasil passou a seguir, na medida do possível, várias orientações dos editais de seleção de dicionários.

O outro aspecto fundamental inovador reside na exigência de compatibilidade entre a estrutura da proposta lexicográfica e o nível de aprendizado dos alunos. Encontram-se aí profundas modificações estruturais que atingem a composição da nomenclatura, as informações do verbete, o nível redacional das definições entre outros elementos importantes. Com isso, rompe-se a grande barreira de que o usuário 
do dicionário é um sujeito indefinido e, ao mesmo tempo, capaz de compreender todo o código lexicográfico que ordena os verbetes. E nele as informações oferecidas sejam elas de natureza linguística ou de teor enciclopédico. O consulente projetado deveria ser ainda alguém capaz de compreender o conteúdo das definições, mesmo que elaboradas em linguagem não compatível com seu conhecimento. É reconhecido que os dicionários bem elaborados fazem uma projeção de seus usuários, mesmo não podendo definir com total exatidão o nível cognitivo de seus consulentes. Em síntese, a projeção dos consulentes visados é determinante da estrutura de uma obra lexicográfica e consiste num fator potencialmente qualitativo.

Nessa direção, o PNLD, ao definir requisitos necessários à tipologia proposta, contribuiu largamente para uma estruturação lexicográfica orientada para diferentes níveis de aprendizagem. De fato, essas determinações foram fundamentais para a melhoria dos dicionários destinados à escola; mas isso não significa, na prática, o alcance de graus de excelência no absoluto. Há ainda bom caminho a percorrer; contudo, o Ensino Fundamental brasileiro, público e também privado, e mais recentemente o Ensino Médio com o PNLD de 2012 foi beneficiado pelos novos formatos dos dicionários que podem ser chamados de escolares. Tudo isso, a despeito dos interesses econômicos das editoras concorrentes ao PNLD. Confirma-se assim o modo como Duran e Xatara (2007) consideram o foco da Lexicografia Pedagógica, ou seja, oferecer subsídios para o aperfeiçoamento de dicionários, considerando as habilidades dos usuários de modo a atender às necessidades linguísticas do seu público-alvo.

Um resultado significativo dessa política lexicográfica é que, agora, ao invés de se falar em dicionário escolar, como minidicionário, passou-se a identificar aqueles apropriados à escola ou de uso escolar. Além disso, as escolas passaram a receber acervos lexicográficos compostos pelos vários tipos agora reconhecidos como dicionários escolares. De algum modo, visualiza-se uma categoria de dicionários 
elaborados com princípios de adequação ao ensino. Essa é uma realidade que amplia o quadro de tipologias dicionarísticas no país e preenche um vazio. Isso porque, como há muito Damin (2005) mostrou, os estudos clássicos de tipologia lexicográfica não incluíam a categoria dicionário escolar.

Todas as observações anteriores, focalizando - produção acadêmica e produção editorial - atestam importantes avanços da Lexicografia Pedagógica no Brasil. Falta, no entanto, chegar mais perto do professor de modo a contribuir para sua formação docente, levando-o a tornar o dicionário um material didático útil para seus projetos de ensino. Tais propósitos são desafios que precisam ser enfrentados para a concretização efetiva da Lexicografia Pedagógica no Brasil.

\section{Dicionário: uma obra desconhecida}

Pode parecer contraditório, mas o dicionário é um tipo de obra que, em princípio, dispensa apresentações. Embora, de longa data, conhecido como o lugar que registra as palavras "existentes" de um idioma e que oferece múltiplas informações linguísticas e culturais, o dicionário é uma obra de consulta, informativa em sua essência, porém seu potencial didático não chega a ser devidamente conhecido, logo, não é explorado. Em geral, a utilização deste tipo de obra limita-se ao domínio do manejo da ordem alfabética, a uma rápida olhada no conteúdo do verbete, a uma simples conferência sobre a existência ou não de alguma palavra ou sintagma e, em geral, à sua grafia. Contudo, indiscutivelmente, o dicionário é "um lugar privilegiado de lições sobre a língua e a linguagem" (KRIEGER, 2012, p. 19) e, como tal, não se resume a uma lista de palavras.

$\mathrm{Na}$ realidade, o papel pedagógico que uma obra dicionarística pode desempenhar depende das condições de sua utilização. Não custa reiterar que esta será mais produtiva, se não ficar limitada à conferência do correto/incorreto, mas avançar em análises sobre as unidades lexicais, seus usos e estruturas gramaticais e 
sintáticas a elas relacionadas, além dos muitos fenômenos do sentido. Reduzir, portanto, a utilização do dicionário ao seu papel de código normativo é limitar seu potencial de instrumento que oferece ensinamentos sobre a língua e sobre a linguagem.

A limitação de uso está, em muito, vinculada à falta de formação docente em Lexicografia. No Brasil, os cursos de magistério, bem como os cursos superiores de Letras não costumam incluir Lexicografia como disciplina curricular. Consequentemente, um dos reflexos negativos da ausência de um conhecimento docente mais aprofundado sobre as obras lexicográficas implica o fato de que o aluno não é levado a compreender mais profundamente a riqueza de um dicionário, o que provoca o desconhecimento de seu potencial informativo sobre a língua, a linguagem e a cultura, bem como se lê:

Pero el hecho de reconocer que se está usando algún diccionario no es, en absoluto, indicativo del grado de familiaridad de los escolares con este tipo de obras; pues al tratarse de un instrumento de consulta y no de un manual o de un libro de texto cuya lectura sea obligatoria, la frecuencia de uso puede llegar a ser extremadamente variable si descendemos a los casos concretos. (AZORIN FERNANDES, 2007, p. $172)^{4}$.

Tal situação é também recorrente no Brasil. Inegavelmente, há razões que deixam o docente e também o aluno carentes de estudos lexicográficos mais sistemáticos. Diante dessa realidade, minimizar a carência docente sobre as muitas possibilidades de aproveitamento do dicionário pelos alunos torna-se um dos principais desafios da LP. Trata-se de difícil missão que pode ser facilitada com a produção de materiais orientadores do uso de dicionários. Nessa direção, há um marco

\footnotetext{
${ }^{4}$ Mas o fato de reconhecer que se está usando algum dicionário não é, em absoluto, indicativo do grau de familiaridade dos estudantes com esse tipo de obras; porque, ao se tratar de um instrumento de consulta e não de um manual ou de um livro de texto cuja leitura seja obrigatória, a frequência de uso pode tornar-se extremamente variável se observarmos casos concretos. (Tradução nossa).
} 
inicial importante que merece destaque pela proposta e abrangência, também publicação do MEC como complementação essencial do PNLD. Trata-se de Com direito à palavra: dicionários em sala de aula (BRASIL, 2012) ${ }^{5}$, texto direcionado aos professores que apresenta informações sobre os dicionários e os acervos, além de propostas de atividades para serem desenvolvidas em sala de aula.

Na mesma direção, elaborou-se uma proposta, logo exemplificada, que se soma ao quadro das já existentes. A motivação maior, e não poderia ser diferente, é auxiliar o docente no cumprimento da missão de tornar os dicionários escolares conhecidos e aproveitados em seu potencial didático. Tal missão inicia por tentar superar o desconhecimento sobre a estrutura organizacional dos dicionários, que corresponde ao tradicional código lexicográfico. Isso inclui as regras de lematização, a identificação, por exemplo, dos princípios de apresentação das acepções entre tantos outros recursos comuns à organização lexicográfica.

Diferentemente do que se costuma julgar, é comum que o aluno não seja um usuário habilitado a consultar as informações que o dicionário oferece. Daí por que o necessário processo de identificação das regras lexicográficas tradicionais tem sido chamado, por vezes, de letramento lexicográfico. Este também é um dos aspectos que a proposição, a seguir apresentada, levou em consideração.

\section{Uma proposta aplicada}

Tal como, já referido, a aplicação de princípios da LP motivou a elaboração de um conjunto de 90 exercícios voltados ao ensino da língua portuguesa, publicados no formato de um Caderno Interativo: atividades com o dicionário (KRIEGER; MÜLLER, 2017). O objetivo maior da publicação consiste em auxiliar o professor a proporcionar ao discente uma experiência concreta de aprendizagem, fazendo o dicionário valer

\footnotetext{
${ }^{5}$ Elaborado por Egon Rangel.
} 
como efetivo material didático. Para tanto, foram privilegiadas relações entre os registros que o dicionário faz - semânticos, linguísticos e discursivos - e algumas possibilidades de aproveitamento pelo aluno das "lições" que a organização e o uso do dicionário oferecem. (KRIEGER; MÜLLER, 2017, p. 5-6).

O exame dessas relações foi orientado pela identificação de conteúdos e competências a serem desenvolvidos no Ensino Fundamental em suas séries finais, público-alvo para as atividades criadas. Especificamente, foram consideradas as principais diretrizes dos Parâmetros Curriculares Nacionais (PCNs) para essa faixa etária. Além, disso, por método de amostragem, foram também observadas algumas diretrizes curriculares municipais, disponíveis na internet.

Em conformidade com os postulados da LP, vale reiterar a importância da adequada exploração de conteúdos em cada nível e projeto pedagógico em pauta para um bom resultado na sala de aula. Nessa perspectiva, as atividades propostas no Caderno não pretendem ser uma fórmula única a ser aplicada sem adaptações. Diferentemente, são exemplos de exercícios a serem selecionados adequadamente conforme o plano de ensino. Cabe, pois, ao docente avaliar a funcionalidade de aplicação, considerando, por exemplo, alguns focos prioritários de ensino como: a) alfabetização e letramento; b) desenvolvimento da competência de leitura e de produção textual; e c) descrição da língua.

Em relação à (a) alfabetização e letramento, o dicionário favorece a identificação do alfabeto e sua ordenação, bem como as bases da silabação. A consulta ao dicionário permite mostrar também que a escrita não é representação direta, mas convencionada da fala.

No plano do $(b)$ desenvolvimento da competência de leitura e de produção textual, são múltiplos os recursos que o dicionário oferece a iniciar pela informação a respeito do sentido único ou dos vários significados das palavras, com seus usos denotados e conotados ou figurativos. Os contextos sociais de uso das palavras também aparecem 
pelo registro das abreviaturas de popular, formal entre outros. Esse tipo de informação auxilia na orientação da escolha de palavras em conformidade com gêneros textuais, atribuindo coesão aos textos produzidos.

De igual modo, a dimensão semântica, articulada pelas definições e pelas redes de acepções nos casos de polissemia, torna ainda mais evidente o importante papel dos contextos para a determinação dos significados. Nessa direção, a prática de desenvolver análise crítica sobre qualidade de definição auxilia no amadurecimento do pensamento lógico e na busca da coerência textual. Daí também a importância de observar as relações de forma e de conteúdo entre palavras: cognatos, sinônimos, antônimos, homônimos. Tudo isso cobre elementos linguísticos e semânticos, cujo conhecimento contribui para uma performance comunicativa mais avançada, amparada pela natural ampliação de vocabulário do aluno.

Por outro lado, o dicionário possibilita desenvolver estudos que envolvem (c) $a$ chamada descrição da língua. Isso inclui o conhecimento das categorias gramaticais, de regência verbal, bem como podem ser analisados aspectos morfológicos sobre: i) formação do léxico: morfologia, etimologia, neologia; e ii) constituição heterogênea do léxico: termos técnico-científicos, áreas de especialidade. Muitas outras possibilidades podem ser exploradas, incluindo a observação da transitividade verbal com os respectivos exemplos.

Diante desse quadro, os exercícios elaborados foram divididos em 2 (dois) eixos básicos assim intitulados: 1) Para conhecer e consultar o dicionário; e 2) Para aproveitar o dicionário. O conhecimento das partes que integram e estruturam um dicionário são os aspectos observados e potencializados no primeiro eixo das atividades, as quais cobrem o letramento lexicográfico. Por sua vez, no segundo eixo, privilegiam-se questões que mostram a produtividade do dicionário no desenvolvimento da competência linguística e textual dos alunos. Apesar dessa divisão metodológica, nos dois eixos, há questões que incidem sobre componentes que possuem implicações 
mútuas. Entretanto, o foco de estudo é distinto. Como ilustração da proposta, são reproduzidas algumas atividades em sequência.

\section{Eixo 1- Para conhecer e consultar o dicionário}

A competência discente no manejo lexicográfico é condição primeira para um bom aproveitamento da obra. De modo simples, é importante que o aluno encontre-se na obra e que ele consiga localizar as informações de que precisa no momento da consulta. Ao obter êxito nos resultados da busca, o dicionário pode se tornar seu aliado permanente, uma ferramenta de auxílio para sua proficiência por toda a sua vida. Donde a importância do letramento lexicográfico, ilustrado nas figuras 1, 2 e 3.

Figura 1 - Dicionário é um livro.

1. Marque com um $\mathbf{X}$ as opções corretas sobre as partes que compõem o seu dicionário.

a) ( ) apresenta um sumário para que você possa se localizar melhor.

b) ( ) tem uma explicação de como usar o dicionário no início da obra.

c) ( ) apresenta a lista dos municípios.

d) ( ) tem uma lista de palavras com as suas definições.

2. Marque $\mathrm{V}$ (verdadeiro) ou $\mathrm{F}$ (falso) nas opções abaixo sobre o dicionário.

a) ( ) apresenta pequenos contos literários.

b) ( ) apresenta a relação dos nomes dos presidentes do país.

c) ( ) tem uma lista com as siglas e abreviaturas utilizadas no interior dos verbetes.

d) ( ) apresenta uma lista com as fórmulas matemáticas.

Fonte: Krieger e Müller, 2017, p. 7.

Figura 2 - Localizando-se no dicionário.

7. Vamos localizar as palavras? Consulte o verbete dicionário na sua obra. Para localizar, utilize as dedeiras de seu dicionário e vá até a letra $d$. Depois, verifique as letras que se seguem ao d para localizar a palavra na página.

Leia o verbete correspondente na página e escreva agora, com as suas palavras, o que é e para que serve o dicionário. Ao lado, faça um desenho para ilustrar a sua definição.

Verbete é cada palavra de um dicionário com um conjunto de informações sobre um assunto - a palavra. (Adaptado do Caldas Aulete. Dicionário Escolar).

dicionário

Fonte: Krieger e Müller, 2017, p. 10. 
Figura 3 - Palavras-guia.

9. Você acabou de consultar o verbete dicionário. Agora imagine quais seriam as palavras que poderiam estar nas palavras-guia da página em que você encontrou o verbete dicionário. Imaginou? Agora consulte o dicionário e escreva-as no espaço abaixo.

LEMBRETE: Palauras-guias são as indicações da primeira e da última palaura que a respectiva página do dicionário irá apresentar naquela folha; elas ajudam o aluno a encontrar as palavras na sua ordem alfabética.

Fonte: Krieger e Müller, 2017, p. 11.

Ainda integrando o eixo 1 (um), Para conhecer e consultar o dicionário, incluem-se atividades que envolvem a noção do registro das palavras na sua forma canônica, isto é, a percepção pelo aluno de que as palavras são lematizadas na sua forma primitiva e que, na linguagem, são utilizadas respeitando as regras morfológicas de flexão de número, pessoa, gênero, tempo e modo, como ilustra a figura 4. Já a figura 5, evidencia outro aspecto importante para a hora da consulta e da leitura interpretativa da obra/verbete: a rubrica. O reconhecimento da abreviatura empregada no interior do verbete mostra ao aluno que a palavra é também usada em outros domínios da linguagem, bem como em outros significados, além da denotação primeira. Esse tipo de informação, aliada à de acepção é também de grande valia para a boa consulta.

Figura 4 - Forma canônica.

12. Marque com um $X$ as palavras que você consegue encontrar no dicionário diretamente, sem precisar fazer nenhuma lematização.
( ) peço
( ) pé
( ) caminhas
( ) bonita
( ) primo
( ) fraca
( ) mesas
( ) amores

As palavras sofrem um processo chamado lematização, ou seja, os verbos são registrados no infinitivo e os substantivos e adjetivos no masculino singular, com exceção daqueles que são comuns de dois gêneros.

Fonte: Krieger e Müller, 2017, p. 11. 
Figura 5 - Rubrica.

21. Consulte o verbete garganta que relaciona seis acepções/sentidos para essa palavra. Em todas elas, há uma abreviatura indicando usos de campos específicos, como anatomia na primeira (Anat.), uso figurativo (Fig.), além de uso popular (Pop.), entre outros. Com base nas informações do verbete, relacione uma coluna com a outra:
(1) Anatomia
a) ( ) Tudo o que ele disse, foi pura garganta.
(2) Geografia
b) ( ) Ele espera que sua garganta esteja bem no dia de sua apresentação.
(3) Uso figurativo
c) ( ) Não dá para suportar aquele garganta.
(4) Uso popular
d) ( ) Eles passaram pela garganta do penhasco.

Fonte: Krieger e Müller, 2017, p. 14.

\section{Eixo 2 - Para aproveitar o dicionário}

O eixo 2 busca potencializar o aproveitamento do dicionário. Donde, atividades que objetivam auxiliar, por exemplo, no desenvolvimento da competência linguística e discursiva do aluno, implicando a ampliação de sua competência lexical. Com esse intuito, o exercício da figura 6 sobre a rede de acepções do verbete visa a evidenciar os efeitos semânticos de cada adjetivo no seu contexto de uso. Já o exercício da figura 7 retoma os mecanismos de consulta ao dicionário, mas privilegia o exame do processo de flexão dos substantivos. Em sequência, a figura 8, propõe o exame de acepções para identificação da melhor definição de acordo com o contexto de uso. Em conjunto, os três exemplos mostram o potencial do léxico em uso.

Figura 6 - Ampliando o léxico e aumentando a competência na língua. 2. Leia atentamente os fragmentos da notícia abaixo:

Embora muita gente ache que conto ${ }^{1}$ lenda $^{2}$ e mito $^{3}$ é tudo a mesma coisa, posso afirmar que não é bem assim. Há vários pesquisadores que estudam essas categorias, porque elas fazem parte da cultura $^{4}$ de um povo. E não existe povo que não tenha o que contar, que não tenha uma só lenda ou um só mito. [...]

Disponivel em: http://chc.org.br/por-que-conto-lenda-e-mito-nao-sao-a-mesma-coisa/. Acesso em: 26 jun. 2017. Escreva um adjetivo para qualificar cada uma das palavras sublinhadas na noticia. Consulte o dicionário se tiver dúvidas.

1. conto:

2. lenda:

3. mito:

4. cultura:

Fonte: Krieger e Müller, 2017, p. 14-15. 
Figura 7 - Substantivos flexionados no dicionário. 5. Sublinhe os substantivos que fazem parte do texto da poesia a seguir. Após, escreva a forma gráfica como você os encontrará no dicionário.

\section{PLANTAR UMA FLORESTA \\ Quem planta uma floresta planta uma festa.}

Planta a música e os ninhos faz saltar os coelhinhos. [...] Luísa Ducla Soares A gata Tareca e Outros Poemas Levados da Breca

Figura 8 - Exame de acepções.

6. A partir das respostas do exercício anterior, procure no dicionário o significado para cada substantivo identificado. Para isso, observe o contexto de uso do substantivo na poesia e a correta acepção no dicionário.

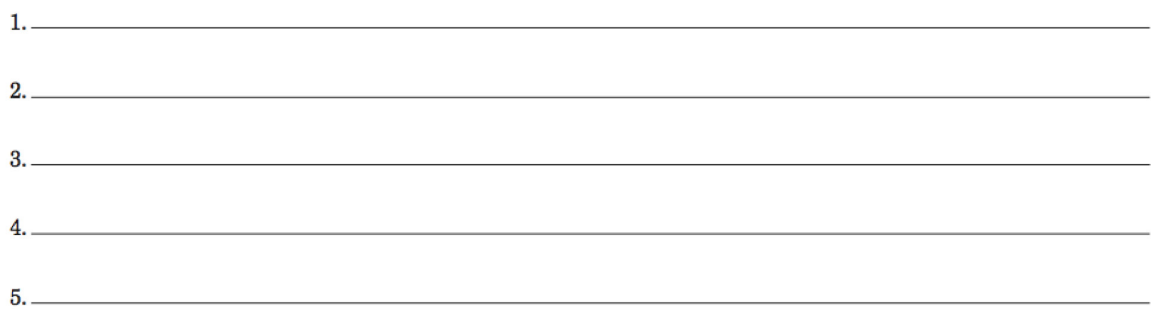

Fonte: Krieger e Müller, 2017, p. 17.

\section{O trabalho com aspectos semânticos é sempre de vital importância e pode servir} a muitos propósitos como a compreensão da importância dos contextos de uso como mostra o exemplo da figura 9.

Figura 9 - Contexto de uso.

47. Observe esta antiga propaganda de goma de mascar:

"Todo o desportista ganha, mascando durante os treinos, durante as provas. Chicletes, as deliciosas pastilhas elásticas de mascar. Reduzem a fadiga e são deliciosos!”

Disponivel em: https://goo.gl/nKGSLV. Acesso em: 06 jun. 2017.

Considerando o sentido geral do texto acima, a palavra fadiga equivale à definição de:

a) ( ) agitação: Ação ou resultado de agitar(-se).

b) ( ) cansaço: Estado físico ou mental de quem se cansou, de quem está com falta de energia, disposição ou concentração, por ter feito grande esforço ou devido a doença.

c) ( ) euforia: Estado de ânimo que, embora caracterizado por grande e expansiva alegria, não corresponde necessariamente à realidade de quem o experimenta.

d) ( ) indisposição: Mal-estar passageiro. Falta de disposição, de ânimo. Falta de entendimento. Má vontade com ou aversão a algo ou alguém.

Fonte: Krieger e Müller, 2017, p. 26. 
Interligados à compreensão do contexto de uso, há dois fenômenos recorrentes nos usos da língua, cujas bases o dicionário auxilia a conhecer: a polissemia e a homonímia. Ambas recebem registros diferenciados na tradição da Lexicografia. A polissemia está equacionada num mesmo verbete e permite analisar as relações associativas que respondem pelos significados diferentes que um mesmo item lexical comporta. Diferentemente, no caso da homonímia, os significados distintos não têm relação associativa, por isso aparecem em entradas independentes. Questionamentos dessa ordem estão contemplados no exercício da figura 10.

Figura 10 - Homonímia e polissemia.

48. Analise os verbetes primo ${ }^{1}$ e primo ${ }^{2}$. Marque as alternativas corretas:

a) ( ) Duas palavras sinônimas.

b) ( ) Duas palavras homônimas.

c) ( ) Duas palavras antônimas.

d) ( ) Duas palavras iguais com significados que não tem relação entre si.

49. Analise o verbete fera, nele há 4 acepções. Compare fera com os verbetes primo ${ }^{1}$ e primo ${ }^{2}$ para dar sua resposta. Justifique a razão de primo ter 2 verbetes (1 e 2) e fera só um verbete apesar de 4 significados:

a) ( ) é um erro do dicionário.

b) ( ) primo deveria ser um só verbete com duas acepções.

c) ( ) quando há relação de sentido entre as acepções, todas ficam no mesmo verbete.

d) ( ) quando não há relação de sentido entre as acepções, são feitos verbetes próprios.

Fonte: Krieger e Müller, 2017, p. 26.

O plano da descrição linguística pode ser exemplificado com os processos de formação de palavras, incluindo a formação deverbal, cujo domínio é também útil para a produção textual qualificada. Isso é destacado no exercício da figura 11. Por sua vez, a criação lexical por prefixação e sufixação também é tópico exemplificado em especial na figura 12. Na 13, nessa seara de formação lexical, está o reconhecimento das famílias de palavras. 
Figura 11 - Formação de palavras - substantivo deverbal.

10. Observe as frases abaixo:

- Pedro embrulhou o presente.

- Pedro colocou o presente no embrulho.

Na primeira frase, a palavra "embrulhou" é um verbo e significa "envolver em papel, pano etc., para formar pacote." (Caldas Aulete - Dicionário escolar da lingua portuguesa). Na segunda, a palavra "embrulho" é um substantivo e é definido pelo dicionário como um "objeto que foi embrulhado, colocado em invólucro; pacote." (Caldas Aulete - Dicionário escolar da língua portuguesa). Esse fenômeno que você observou é algo muito comum na língua. Usam-se palavras que já existem para que novas sejam criadas a partir dela. Aí tem-se o processo de formação de substantivos a partir de verbos, os chamados substantivos deverbais.

Agora complete as lacunas das frases seguintes com os respectivos substantivos criados a partir dos verbos do primeiro período. Para isso procure o verbo sublinhado no dicionário e, a partir dele, localize o respectivo substantivo.

a) As enchentes do sul do país destruíram muitas escolas da região. A causada foi enorme e muitos alunos ficaram sem aulas.

b) $O$ jogador luxou seu ombro durante a partida de futebol. A foi muito grave e ele teve que ser removido do campo.

c) Durante as atividades recreativas da festa da escola, muitos alunos gritavam para que seus colegas ouvissem as instruções da brincadeira. Os d) Os ladrões fugiram pelo túnel. A podiam ser ouvidos da sala da direção.

Fonte: Krieger e Müller, 2017, p. 18.

Figura 12 - Formação de palavras - prefixos.

30. Marque as alternativas em que só uma palavra não tem o sentido do prefixo tri-:

a) tri, tríade, triângulo,

b) tridimensional, triatlo, tribunal

c) triciclo, trilho, trindade

d) trinado, trincar, trilhão

Fonte: Krieger e Müller, 2017, p. 23.

Figura 13 - Formação de palavras - família de palavras.

28. Assinale as alternativas em que uma palavra não é da mesma família:

a) verdade, veracidade, verossímil

b) verdade, verdadeiro, inverdade

c) verídico, veraz, verberar

d) inverdade, verídico, verdadeiro

Fonte: Krieger e Müller, 2017, p. 22.

No mesmo plano de descrição e funcionamento da língua, pode ser contextualizado o trabalho com classes de palavras. Isso permite ao professor explorar a noção de que o uso de classes gramaticais não é aleatório, mas há condições de uso semânticas e sintáticas. A identificação dessas condições, com ênfase nos aspectos de regência, está prevista nos exercícios das figuras 14 e 15, neste último, incluídos os verbos impessoais fazer e haver. A categoria dos pronomes também é explorada no exercício da figura 16. 
Figura 14 - Classe dos verbos.

13. Os verbos abaixo possuem mais de um significado, podendo ter também uma dupla regência. Encontre no dicionário dois significados diferentes para cada verbo. Indique a regência verbal e crie ao lado uma frase para cada um dos sentidos do verbo.

a) acordar:

b) descobrir:

c) contrair:

d) pegar:

Fonte: Krieger e Müller, 2017, p. 19.

Figura 15 - Regência verbal.

64. Consulte os verbos abaixo no seu dicionário. Escreva um exemplo de uso para cada acepção que o dicionário traz. Preste bastante atenção nos sentidos estabelecidos e na regência dos verbos.

a) haver

Como verbo impessoal:

Ideia de dever, possibilidade:

Sentido de ter:

b) fazer

Criar, elaborar, produzir:

Como verbo impessoal no sentido de tempo decorrido:

Como verbo impessoal seguindo indicação de fenômeno atmosférico:

c) ser

Ter determinada característica, especialidade:

Pertencer:

Como verbo impessoal na indicação de hora, dia:

d) ir

Fazer-se presente; comparecer; frequentar:

Pautar-se ou deixar-se levar por:

Fonte: Krieger e Müller, 2017, p. 29.

Figura 16 - Classes gramaticais: pronomes pessoais.

16. Procure no dicionário as palavras eu (pronome pessoal reto) e mim (pronome pessoal oblíquo) e preencha as lacunas com o pronome adequado de acordo com a sua correta indicação de uso.

a)_ acordo muito cedo.

b) Isso fica entre __ e você

c) posso ir com vocês?

d) Escolheram a

Fonte: Krieger e Müller, 2017, p. 19. 
Uma forma de trabalhar várias características das palavras é refletir sobre as informações registradas no interior de um mesmo verbete, além de propor a comparação com outro, como mostra a figura 17. Disso pode decorrer o entendimento do processo de formação lexical, o contexto de uso especializado ou geral das palavras pela sua definição e pelas rubricas que integram a cabeça do verbete, e, naturalmente, as diferenças de sentido que existem de acepção para acepção e de palavra para palavra. Registra-se ainda que o exame desse tipo de verbete permite o trabalho com termos das diferentes disciplinas do currículo escolar.

Figura 17 - Rubrica: uso especializado.

54. Leia os verbetes parra e parreira e marque V (verdadeiro) ou $\mathrm{F}$ (falso):

parra (par.ra) sf. Bot. Galho de videira. [F.: De or. $\quad \begin{gathered}\text { parreira (par.rei.ra) sf. Bot. Nome dado a plantas tre- } \\ \text { padeiras, esp. a videira. [F.: parra + eira.] }\end{gathered}$
contrv.]

a) ( ) os dois verbetes são termos da botânica, pois trazem a marca Bot.

b) ( ) os dois verbetes são da mesma família de palavras.

c) ( ) os dois verbetes tem o mesmo significado.

d) ( ) o segundo verbete é derivado do primeiro verbete, ou seja, foi criado a partir da palavra parra.

Fonte: Krieger e Müller, 2017, p. 27.

Por fim, entre tantas possibilidades de desenvolvimento das competências linguísticas e discursivas dos alunos por intermédio do potencial didático do dicionário, há ainda que se destacar o registro das locuções, expressões e, ainda, fraseologias, as quais passam a integrar o verbete, cuja palavra-entrada integra essas expressões. Tal registro oferece condições ao consulente de entender a expressão no seu contexto de uso conforme exemplificam as figuras 18 e 19.

Figura 18 - Uso de locuções/expressões.

43. No verbete encontro, o dicionário registra o significado de expressões como ir/vir ao encontro de e ir/vir de encontro a. Veja que são significados opostos, mas, em geral, são usados de modo equivocado como sinônimos.

Escreva duas frases com o sentido de cada uma das expressões e explique a diferença entre elas:

a) ir/vir ao encontro de:

b) ir/vir de encontro:

Fonte: Krieger e Müller, 2017, p. 25. 
Figura 19 - Expressões idiomáticas.

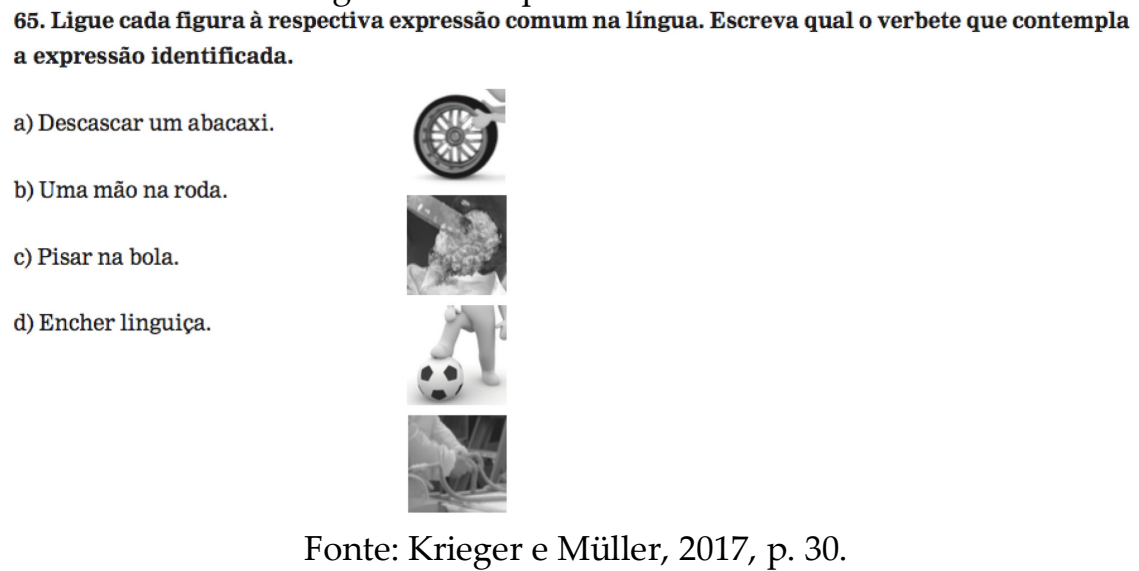

Tal como afirmou-se antes, a elaboração desse conjunto de questões não tem a pretensão de ser modelo, tampouco ser seguido sem questionamentos. A motivação maior sempre foi a de mostrar a produtividade do uso do dicionário para o aprendizado da língua materna, o que ultrapassa o que se elaborou nesta proposta. Compete ao professor refletir sobre as possibilidades de uso de um dicionário na sala de aula e, a partir disso, criar seu panorama de perguntas clássicas ou inovadoras, já que o dicionário é uma grande ferramenta para o ensino da língua. Tanto que permite ao professor valer-se dele para trabalhar com temáticas variadas, desde que se pergunte se pode encontrar caminhos para estudar com seus alunos tópicos como: ortografia, silabação, significados, ideologias? formação de palavras? palavra complexa? expressão idiomática? polissemia? homonímia? origem das palavras? termos técnicos? verbos? pronúncia? classes lexicais e classes gramaticais? estrangeirismos?

Em síntese, o dicionário, pelo conjunto de informações que oferece, é uma obra que ultrapassa de longe a ideia de simples listagem de palavras a que se agregam significados e algumas informações gramaticais. Ao contrário, mesmo com limitações, mostra o uso pleno da palavra, ressaltando a importância da ferramenta que o docente tem em suas mãos. Decorre daí também a relevância da Lexicografia Pedagógica. 


\section{Referências Bibliográficas}

AZORÍN FERNANDES, D. La investigación sobre el uso del diccionario en el ámbito escolar. In: ISQUERDO, A. N.; ALVES, I. M. (orgs). As ciências do léxico: lexicologia, lexicografia, terminologia, vol. 3. Campo Grande; São Paulo: Editora UFMS; Humanitas, 2007.

BRASIL. Ministério da Educação. Secretaria de Educação Básica. Com direito à palavra: dicionários em sala de aula / [elaboração Egon Rangel]. - Brasília: Ministério

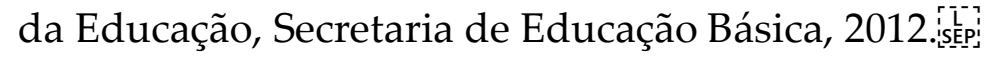

DAMIM, C. P. Parâmetros para avaliação do dicionário escolar. Porto Alegre, UFRGS, 2005. (Dissertação de Mestrado).

DURAN, M. S.; XATARA, C. M. Lexicografia Pedagógica: atores e interfaces. Delta: Documentação de Estudos em Linguística Teórica e Aplicada, São Paulo, v. 23, n. 2, p. 212-222, 2007. DOI: https://doi.org/10.1590/S0102-44502007000200002

KRIEGER, M. G. Dicionário em sala de aula: guia de estudos e exercícios. Rio de Janeiro: Lexikon, 2012.

KRIEGER, M. G.; MÜLLER, A. F. Caderno de Exercícios. Rio de Janeiro: Lexikon, 2017. 